\title{
$\mathrm{R} C \& \mathrm{C}$
}

REVISTA DE CONTABILIDADE E CONTROLADORIA

\section{TRANSPARÊNCIA NOS SITES DOS MUNICÍPIOS DO ESTADO DO RIO DE JANEIRO}

TRANSPARENCY ON THE WEBSITES OF MUNICIPALITIES IN THE STATE OF RIO DE JANEIRO

Recebido em 08.09.2015 | Aceite final em 22.05.2016 |

Nota: este artigo foi aceito pelo Editor Jorge Eduardo Scarpin e passou por uma avaliação double

blind review

A reprodução dos artigos, total ou parcial, pode ser feita desde que citada a fonte.

VANUZA DA SILVA FIGUEIREDO

Mestre em Ciências Contábeis | Universidade do Estado do Rio de Janeiro (UERJ) | Rua Alcyr Amorin, 19 | Bacaxá | CEP: 28993-000| Saquarema - RJ | Telefone: (22) 992764554| Email: vanuzafigueiredo@hotmail.com |

\section{ROSENCLEVER LOPES GAZONI} Doutorando em Engenharia Mecânica | Universidade Federal Fluminense - UFF| Rua José Breves, 550| Centro | CEP: 28993-000| Pinheiral - RJ | Telefone: (24)3356-8242 | Email: rosenclever@gmail.com |

\section{RESUMO}

Este artigo visa contribuir para a reflexão sobre transparência nos sites dos 92 municípios do Estado do Rio de Janeiro. Trata-se de uma pesquisa exploratória e qualitativa. O estudo tem como objetivo analisar a transparência na divulgação das informações relativas a gestão desses municípios, verificando se estão atendendo aos dispositivos da Lei de Acesso à Informação. A população pesquisada abrange exclusivamente os sites oficiais dos municípios do Rio de Janeiro. A análise nos sites foi realizada nos meses de março e abril de 2015. Concluiu-se que as prefeituras estão criando novas opções para ampliar o nível de transparência. Entretanto, há necessidade de um avanço maior nesse aspecto com a finalidade de atender os interesses da coletividade, garantindo o acesso a informações atualizadas e relevantes. A liberação em tempo real de informações pormenorizadas sobre a execução orçamentária 
e financeira, em meios eletrônicos de acesso público, ainda não faz parte da realidade da administração pública.

Palavras-chave: transparência, Lei de Acesso a Informação, accountability.

\begin{abstract}
This article aims to contribute to the debate on transparency on the sites of the 92 municipalities in the state of Rio de Janeiro. This is an exploratory and qualitative research. The study aims to analyze the transparency in the disclosure of information concerning the management of these municipalities, verifying whether they are meeting the provisions of the Access to Information Act. The research population covers only the official websites of the municipalities of Rio de Janeiro. The analysis on the sites was carried out in March and April 2015. It was concluded that local governments are creating new options to increase the level of transparency. However, there is need for greater progress in this regard in order to meet the interests of the community, ensuring access to updated and relevant information. The release real-time detailed information on the budgetary and financial execution in publicly accessible electronic means is not yet part of the public administration reality.
\end{abstract}

Keywords: Transparency, Access to Information Act, accountability.

\title{
1- INTRODUÇÃO
}

As constantes denúncias de corrupção e mau uso da máquina pública tornaram-se comuns na administração pública brasileira. Essa situação deixa o cidadão perplexo diante do descaso, falta de respostas e punição dos envolvidos. Por isso, iniciou-se a busca e demanda por mais transparência dos atos de seus representantes. Assim, o acesso da sociedade a informações referentes à administração dos recursos públicos permite a verificação dos gastos e se estão sendo utilizados adequadamente, atendendo aos interesses coletivos. Além disso, a cobrança da sociedade por visibilidade está vinculada à necessidade de ter acesso ao conteúdo informacional dos atos e gastos efetivados pelo governo, afinal, o conhecimento pleno daqueles atos, por si só, não atende às expectativas do cidadão, que, também, exige qualidade informacional, em espaço temporal.

A confiabilidade da informação tornou-se uma das reivindicações da sociedade, pois há necessidade de identificar os requisitos, critérios e avaliação das informações divulgadas. O Comitê de Transparência é responsável pela elaboração dos critérios e parâmetros técnicos do índice de Transparência, cujo objetivo é criar um ranking, que elenca portais com maior ou menor grau de transparência. Esse Comitê é formado por especialistas em finanças e contas públicas. O Índice de Transparência foi criado para informar ao cidadão o nível de transparência das contas públicas apresentadas na internet e tem como objetivo apresentar um ranking dos sites mais transparentes. 
O Brasil atualmente possui diversas Leis sobre a transparência e publicidade de sua gestão como: Lei $n^{\circ} 12.527$, Decreto $n^{\circ} 7.185$ que dispõe sobre o padrão mínimo de qualidade do sistema integrado de administração financeira e controle, no âmbito de cada ente da Federação, Lei Complementar $n^{\circ} 101$ de 2000 e 131 de 2009, a Constituição Federal e Decretos Municipais, Estaduais e Federais regulamentando a Lei de Acesso à Informação. No entanto, o Brasil pelo ranking de Transparency International alcançou a posição 69 no ano de 2014. A Transparency International está presente em mais de 100 países, despertando a consciência coletiva dos povos em busca de mudança. Essa organização internacional, com base na opinião de especialistas de todo o mundo, elabora a Corruption Perceptions Index que mede os níveis percebidos de corrupção no setor público em vários países.

O Índice de Transparência utiliza como base a Lei Complementar 131, decreto 7.185 e a Lei de Responsabilidade Fiscal (LRF). O Ministério Público Federal (MPF) em São João de Meriti (RJ) criou o seu ranking, com base nas Leis utilizadas pelo Comitê e na Lei de Acesso à Informação (Lei 12.527/11). A pesquisa realizada apontou que nenhuma das oito cidades avaliadas estavam cumprindo integralmente a Lei 12.527/11.

A Lei de Acesso à Informação determina que a União, Estados, Distrito Federal e Municípios utilizem todos os meios e instrumentos legítimos de que dispuserem, sendo obrigatória a divulgação em sítios oficiais da rede mundial de computadores (internet). A internet tornou-se um instrumento eficaz para o acompanhamento das ações dos gestores públicos. Como afirma Vicente e Scheffer (2014) a internet é uma ferramenta indispensável no processo de democratização da informação, essencial para o controle democrático, para a participação popular e para efetividade da governança no setor público.

A pesquisa sobre a transparência na gestão pública se destaca devido à necessidade de verificar se os municípios do Estado do Rio de Janeiro estão atendendo a legislação, assim como analisar as informações divulgadas. A transparência nos sites permite que o cidadão acompanhe a gestão pública, analise os procedimentos de seus representantes e favoreça o crescimento da cidadania, trazendo às claras informações anteriormente veladas nos prédios públicos. Um Estado transparente possibilita a redução dos desvios de verbas e o cumprimento das políticas públicas, proporcionando benefícios para toda a sociedade.

Uma administração transparente permite a participação do cidadão na gestão e no controle da administração pública e, para que essa expectativa se torne realidade, é essencial que ele tenha capacidade de conhecer e compreender as informações divulgadas. É necessário analisar se os municípios estão cumprindo as determinações legais a respeito de transparência. O estudo busca verificar nos sites oficiais o nível de transparência apresentado pelos 92 (noventa e dois) municípios do Estado do Rio de Janeiro.

Assim este estudo se justifica em razão de apresentar um assunto relacionado a transparências das informações públicas, dentre elas as informações financeiras. Os gestores são eleitos e remunerados para administrar os recursos públicos. A prestação de contas da gestão realizada pelos representantes da população é essencial. A cobrança da sociedade por visibilidade está vinculada à necessidade de abrir acesso ao conteúdo informacional dos atos e gastos efetivados pelo governo. 0 conhecimento daqueles atos, por si só, não atende às expectativas do cidadão, que, também, exige qualidade informacional, em espaço temporal.

Na pesquisa realizada nos sites dos municípios gaúchos, identificou-se no site que as informações não estavam de forma clara e não possuíam uma abordagem vinculada à cidadania, respeitando as especificidades dos usuários portadores de deficiência, para os quais já existem softwares à 
disposição. (MARENGO e DIEHL 2011). Uma sociedade participativa e consciente da atuação dos seus representados, desempenha de forma mais satisfatória o exercício da democracia quando tem o livre arbítrio de opinar e fiscalizar os gastos públicos.

Diante do exposto, pretende-se investigar o seguinte problema de pesquisa: Qual o nível de transparência dos sites das prefeituras do Estado do Rio de Janeiro?

Para solução do problema levantado pela pesquisa, este estudo desenvolverá as seguintes hipóteses:

- Os sites das prefeituras do Estado do Rio de Janeiro apresentam transparência plena dos dados de sua gestão;

- Os sites das prefeituras do Estado do Rio de Janeiro são parcialmente transparentes;

- Os sites das prefeituras do Estado do Rio de Janeiro apresentam baixo nível de transparência.

Para alcançar a solução do problema apontado, esta pesquisa tem como objetivo geral analisar a transparência na gestão dos municípios do Estado do Rio de Janeiro por meio dos seus sites oficiais.

Como objetivos específicos, a pesquisa deverá:

- Descrever a legislação sobre transparência e publicidade na gestão pública;

- Analisar e fornecer um parecer baseado no cumprimento de cada quesito nos sites oficiais dos municípios do Estado do Rio de Janeiro a transparência das informações referentes às exigências da Lei de Transparência.

A organização deste estudo está compreendida em três seções além da Introdução que apresenta a justificativa, o problema de pesquisa, hipóteses de solução e os objetivos geral e específico. A primeira seção aborda o referencial teórico, com a conceituação do tema e descrição da legislação brasileira sobre transparência na gestão pública. A segunda seção apresenta a metodologia aplicada. A terceira refere-se à análise das características dos sites oficiais dos 92 (noventa e dois) municípios do Estado do Rio de Janeiro e a quarta apresenta as considerações finais.

\section{2- REFERENCIAL TEÓRICO}

\subsection{LEI DE RESPONSABILIDADE FISCAL}

A Constituição da República Federativa do Brasil (CRFB/88) já determinava a obrigatoriedade da publicidade dos dados públicos e essa divulgação de dados favorece o acompanhamento da gestão pública. A CRFB/88 auxiliou a transparência e a divulgação dos dados públicos. O seu Art. 37 afirma que "A administração pública direta e indireta de qualquer dos Poderes da União, dos Estados, do Distrito Federal e dos Municípios obedecerá aos princípios da legalidade, impessoalidade, moralidade, publicidade e eficiência". Através da publicidade a coletividade poderá ter acesso às informações referentes aos atos executados por seus representantes.

A Lei Complementar 101/2000 foi sancionada para normatizar as finanças públicas voltadas para a responsabilidade na gestão fiscal. Antes da Lei de Responsabilidade Fiscal o país apresentava um alto 
grau de endividamento, constantemente identificavam titulares finalizando seu mandato com várias irregularidades na sua gestão. Esta Lei destaca também a necessidade de transparência na administração pública, aos quais será dada ampla divulgação, inclusive em meio eletrônico de acesso público.

Em 2009 a Lei Complementar 131 veio alterar a Lei de Responsabilidade Fiscal e destacar novas abordagens da transparência como a liberação ao pleno conhecimento e acompanhamento da sociedade, em tempo real. Uma informação desatualizada e incompleta não atende as exigências sociais, tal como as convicções que norteiam o efetivo controle social.

Para Sacramento e Pinho (2008) a LRF integra o rol das medidas que contribuem para o avanço formal da transparência na administração pública e a sua efetivação depende diretamente do exercício da fiscalização de seu cumprimento pelos órgãos de controle (Legislativo, Tribunais de Contas e Ministério Público) aliados a uma ampla participação popular, que como se sabe, ainda carece de arenas apropriadas para tal exercício.

As informações referentes a receita e despesa pública deverão ser disponibilizadas a qualquer pessoa física ou jurídica. A Lei apresenta o cidadão, partido político, associação e sindicato como partes legitimas para denunciar ao respectivo Tribunal de Contas e ao órgão competente do Ministério Público sobre o descumprimento das determinações da Lei de Responsabilidade Fiscal. Contudo, observamos que poucos brasileiros têm consciência de seus direitos.

\section{2 . LEI DE ACESSO À INFORMAÇÃO}

A Lei de Acesso à informação $\mathrm{N}^{\circ} 12.527 / 11$ (LAl) foi um dos esforços da legislação brasileira para regrar a transparência no Brasil. Essa Lei entrou em vigor e várias entidades não estavam preparadas para a nova realidade. Seu propósito é regulamentar o acesso a informações previstas no inciso XXXIII no artigo 5, no inciso II do $\S 3$ do art.37 e no $\S 2$ do art.216 da Constituição Federal de 1988 que fala sobre os direitos constitucionais sobre o tema transparência.

Todos têm direito de receber dos órgãos públicos informações de seu interesse particular, ou de interesse coletivo ou geral, que serão prestadas no prazo da Lei, sob pena de responsabilidade, ressalvadas aquelas cujo sigilo seja imprescindível à segurança da sociedade e do Estado. Cabem à administração pública, na forma da Lei, a gestão da documentação governamental e as providências para franquear sua consulta a quantos dela necessitem.

A União, Estados, Distrito Federal e Municípios e as entidades privadas sem fins lucrativos que recebam para realizações de ações de interesse públicos, recursos públicos diretamente do orçamento ou mediante subvenções sociais, contrato de gestão, termo de parceria, convênios, acordos, ajustes estão subordinados ao regime da LAl. A pesquisa realizada por Bernardes, Santos e Rover (2015) identificou que, dos 40 sítios que foram avaliados, nenhum atendia à Lei 12.527/11 como um todo e a disponibilização das informações dentro dos sítios não seguia nenhuma estrutura lógica ou padrão preestabelecido.

Uma gestão transparente proporciona um amplo acesso das suas informações, a divulgação torna-se uma regra. $\mathrm{E}$ as tomadas de decisões dos gestores são constantemente acompanhadas por meio da publicidade. As entidades ao cumprir a LAI estão comprometidas a garantir a disponibilidade, autenticidade e integridade das informações. Como afirma Fumega (2014) a chave para a implementação efetiva das leis de acesso à informação consiste na adaptação do modelo à realidade do cidadão usuário da informação. 
As informações apresentadas podem assumir características de transparência ativa ou transparência passiva. Transparência ativa consiste no esforço das entidades em publicar o máximo de informações de interesse gerais nos seus sites, atendendo com isso grande parte da comunidade assistida. $\mathrm{Na}$ transparência passiva as entidades disponibilizam servidores para atender as demandas e pedidos dos indivíduos que solicitaram por detalhamento da informação apresentada ou por novas informações. Como a Controladoria Geral da União CGU expõe os órgãos e entidades devem optar pela transparência ativa quando se tratar de informações de interesse geral. Nos países que possuem Lei de acesso à informação há mais tempo, observa-se que quanto mais informações nos sites, menos pedidos chegam aos órgãos públicos.

Os cidadãos ao encontrar nos sites as principais informações não terão necessidade de realizar pedidos específicos junto a entidade. Hoch, Rigui e Silva (2013) afirmam que a democracia possui relação com a interface digital do Estado, pois a utilização da internet, sobretudo, de sites e portais oficiais, representa hoje o principal canal de informação da esfera pública e civil.

A LAI tem como propósito assegurar o diretito fundamental de acesso à informação e devem ser executados conforme os princípios da administração pública que são legalidade, impessoalidade, moralidade, publicidade e eficiência, tal como as diretrizes de observar a publicidade como receito geral e o sigilo como exceção, divulgação de informações de interesse público, independentemente de solicitações, uso dos meios de comunicação, incentivo ao fomento e desenvolvimento da cultura da transparência e do controle social na administração pública.

\subsection{TRANSPARÊNCIA E ACCOUNTABILITY}

O accountability abrange um conjunto de medidas presentes na administração pública com o intuito de otimizar suas atividades. A ausência de um dos procedimentos compromete a sua total aplicação. Segundo Matias-Pereira (2012) o termo reúne mecanismos e procedimentos que conduzem os dirigentes governamentais a prestar contas dos resultados de suas ações à sociedade, garantindo-se a divulgação das políticas públicas e o aumento do nível de transparência.

Há três formas de accountability: horizontal, vertical e diagonal, aplicáveis ao setor público:

- Accountability horizontal acontece quando funcionários públicos se posicionam na supervisão das ações de outros órgãos do governo (tribunais, comissões de investigação e controladorias) (ACKERMAN, 2004)

- Accountability vertical ocorre quando o eleitorado controla os políticos por meio do voto, de plebiscito ou referendo. Os cidadãos podem punir ou premiar um mandatário votando a seu favor ou contra ele ou os candidatos que apoiem na eleição seguinte (O 'DONNELL, 1998); e

- Accountability diagonal ocorre quando as autoridades de supervisão não exercem nenhuma relação hierárquica direta com organizações públicas e não têm poder para impor sanções (BOVENS, 2006).

Não há um consenso nos trabalhos publicados no Brasil sobre a tradução do termo accountability. 0 estudo de Medeiros, Crantschaninov e Silva (2013) sobre accountability nos periódicos brasileiros das 
áreas de administração, administração pública, ciência política e ciências sociais apontou que os três principais elementos presentes nos conceitos de accountability foram os termos "responsabilização", "prestação de contas" e "transparência".

A construção de portais eletrônicos e o conteúdo que eles apresentam também depende da vontade dos gestores que representam as entidades, que ainda não cultivam o espírito da accountability (RAUPP, 2014). Uma sociedade motivada para exercer o controle social associada a iniciativa de boa governança fortalece o accountability. Como afirma Zheng (2014) a vontade política é importante no desenvolvimento de oportunidades e de participação.

A transparência proporciona um ambiente de análise e reflexão, mas para isso é necessário que os gestores públicos evidenciem suas tomadas de decisões e divulguem-nas nos meios de comunicação acessíveis à população, de forma clara e compreensível não permitindo que suas informações fiquem restritas a alguns servidores e ocupantes de cargos comissionados. Wehner (2013) aponta que fatores políticos internos desempenham um papel primordial na determinação do nível de transparência.

\section{3- METODOLOGIA}

Neste estudo, com relação aos seus objetivos, trata-se de uma pesquisa exploratória, pois busca nos sites oficiais das prefeituras a divulgação de determinados dados. Por abordar característica de uma população é classificada como descritiva, tendo o objetivo de identificar e obter informações sobre as características de um determinado problema ou questão. Quanto à abordagem, a pesquisa se classifica como qualitativa, mas subjetiva. Envolve examinar e refletir as percepções para obter um entendimento de atividades sociais e humanas (COLLIS E HUSSEY, 2005).

A pesquisa exploratória será realizada em artigos científicos, livros, dissertações e sites. Foi utilizado o site do governo do Estado do Rio de Janeiro, para localizar os portais dos 92 (noventa e dois) municípios. A população pesquisada abrange exclusivamente os municípios do Rio de Janeiro. A análise nos sites foi realizada nos meses de março e abril de 2015.

A pesquisa pretende analisar a transparência na divulgação das informações relativas a gestão dos municípios do Estado do Rio de Janeiro, verificando se estão divulgando e atendendo os dispositivos legais, como a utilização obrigatória de site oficiais da rede mundial de computadores (internet) para divulgar informações de interesse coletivo ou geral por eles produzidas ou custodiadas.

O nível de transparência dos sites das prefeituras do Estado do Rio de Janeiro será medido por meio de analise das finanças públicas e adaptação do modelo utilizado pelo critério de transparência adotado pelo Ministério Público Federal em São João de Meriti (RJ) para criar o seu ranking nos municípios da Baixada Fluminense. A pesquisa desenvolvida buscou localizar nos sites respostas para 20 quesitos apontados pela Lei de Acesso à informação atribuindo notas de 0 a 5 . A pesquisa teve algumas limitações como sites em manutenção. Não fez parte do escopo da pesquisa os sites das Câmaras Municipais e da administração indireta. Assim como não foi feito um estudo sobre a regulamentação da Lei de Acesso à Informação Pública nos respectivos municípios.

\section{ANÁLISE DOS DADOS}


O Estado do Rio de Janeiro faz parte da região sudeste do Brasil com uma população aproximada de 16.461.173 habitantes. O Rio de Janeiro representa uma das maiores economias do Brasil. Os municípios mais populosos são: Rio de Janeiro, São Gonçalo, Duque de Caxias, Nova Iguaçu, Belford Roxo, Niterói, São João de Meriti, Campos dos Goytacazes, Petrópolis, Volta Redonda, Magé, Itaboraí, Macaé, Mesquita, Cabo Frio, Nova Friburgo, Angra dos Reis e Barra Mansa.

O Rio de Janeiro é dividido em 92 municípios. Grande parte da economia do Estado se baseia na prestação de serviços e turismo. A pesquisa foi realizada nos sites oficiais das prefeituras de cada município (rj.gov.br). Os municípios voltados para o turismo estão em sua maioria nas regiões da Baixada Litorânea e Costa Verde.

As prefeituras adotam links denominados: transparência, portal da transparência, acesso à informação e serviço de informação ao cidadão. Essas opções estão inseridas nos sites para atender as disposições da Lei Complementar $n^{\circ} 131$, de 27 de maio de 2009, que alterou a Lei Complementar $\mathrm{n}^{\circ}$ 101, de 4 de maio de 2000, o Decreto $\mathrm{n}^{\circ} 7.185$ de 27 de maio de 2010, bem como a Lei de Acesso à Informação Pública (Lei $n^{\circ} 12.527$, de 18 de novembro de 2011). Esses links apresentam-se como ferramenta de controle social que possibilita ao cidadão acompanhar informações sobre a administração pública municipal.

Ao pesquisar nos sites oficiais das 92 prefeituras do Estado do Rio de Janeiro buscou-se localizar a presença dos 20 quesitos abordados na Lei de Acesso a Informação. Para cada quesito foi atribuída uma pontuação de zero a cinco:

1. Como as entidades do poder público viabilizam alternativas de encaminhamento de pedidos de acesso por meio de seus sites oficiais na internet. Alguns municípios apresentam essa possibilidade por meio do link da ouvidoria. $O$ individuo que desconheça a competência da Ouvidoria poderá ter dificuldade para fazer contato com a prefeitura.

2. A entidade utiliza a divulgação nos seus sites oficiais na rede mundial de computadores (internet). O ente possui o link ativo do Portal da Transparência? Todos os municípios apresentaram esse Link, exceto São Francisco do Itabapoana. O site da prefeitura de Saquarema e Aperibé ao selecionar o link portal da transparência dá a mensagem: Esta página da web não está disponível. Nos sites das prefeituras de Rio das Flores, Rio Claro e Nova Friburgo há necessidade de baixar programas, para assim poder acessar os dados no Portal da Transparência. No caso de Belford Roxo, Mendes, Seropédica e Duas Barras o link transparência encaminha a pesquisa para o site da Controladoria Geral da União apresentando dados sobre o município.

3. Foi analisado se há informação da despesa com a indicação do processo licitatório? Apenas $21 \%$ das prefeituras associam as despesas com seus respectivos processos licitatórios.

4. A respeito da indagação sobre a disponibilização no site do registro das competências e estrutura organizacional do ente foi verificado que a grande maioria dos municípios não atribuem as competências de suas secretarias nos seus sites como determina no Inciso I, §1으, art.8으, Lei $12.527 / 11$ da LAI. Apenas $29 \%$ atende plenamente esse quesito.

5. Já o item que trata sobre a disponibilização de endereços e telefones das respectivas unidades e horários de atendimento ao público, identificou-se que apenas $12 \%$ apresentam o horário de atendimento. 
6. No Inciso I, $\S 1$ 으, art.8으, Lei $12.527 / 11$ dispõe sobre a necessidade da entidade apresentar as respostas a perguntas mais frequentes da sociedade, porém apenas Maricá, Piraí, Macaé, Mesquita e Santo Antônio de Pádua atenderam este dispositivo legal.

7. Sobre o site conter ferramenta de pesquisa de conteúdo que permita o acesso à informação de forma objetiva, transparente, clara e em linguagem de fácil compreensão não foi contemplado por nenhum município de forma ampla. Descumprindo o Inciso I, § 3으, Art.8o, Lei 12.527/11.

8. A respeito do site possibilitar a gravação de relatórios em diversos formatos eletrônicos, inclusive abertos e não proprietários, tais como planilhas e texto, de modo a facilitar a análise das informações foi atendido no município de Duque de Caxias, Rio de Janeiro e parcialmente pelas prefeituras de Quatis e Santa Maria Madalena. A grande maioria permite gerar a gravação em um único formato (PDF).

A respeito de licitação, três questionamentos foram feitos. 9. Se existem informações concernentes a procedimentos licitatórios, inclusive os respectivos editais e resultados? 10. Constam informações de licitações abertas, em andamento e a realizar? 11. Há informação nos casos de dispensas e inexigibilidades de licitações? O município que disponibiliza o maior número de informação sobre esse tema é Mangaratiba, Niterói, Resende e Nilópolis.

12. A respeito de informações sobre Contratos e Convênios Celebrados exigido pelo Inciso IV, §1으, art.8ㅇ, Lei 12.527/11. Os municípios que apresentam dados sobre isso de forma ampla foram: São Pedro de Aldeia, Paraty, Niterói, Nova Iguaçu, Resende e Mangaratiba.

13. A divulgação do Quadro Funcional, indicando nome, cargo, local de lotação e forma de investidura (efetivo ou comissionado) ainda não está disponibilizada por todas as prefeituras, exceto Angra dos Reis, Campos dos Goytacazes, Cantagalo, Miguel Pereira, Itaguaí, Paty do Alferes, Resende, Rio das Ostras, São João do Meriti, Tanguá e Três Rios.

14. Os dados que contemplam informações sobre servidores cedidos por outros órgãos foram divulgados pelo município de São João de Meriti.

15. A apresentação de dados sobre despesas com passagens aéreas e diárias concedidas, indicando nome e cargo do beneficiário, destino da viagem, período e motivo da viagem, bem como o número de diárias está presente no site das prefeituras de Carapebus, Comendador Levy Gasparian e Conceição de Macabu.

16. As leis municipais: Os instrumentos constitucionais de planejamento presentes no artigo 165 CF/88 estão presentes em toda administração pública; a Lei Orçamentária Anual (LOA) deve estar compatível com o Plano Plurianual (PPA) e sua elaboração será orientada pela Lei de Diretrizes Orçamentárias (LDO). A LOA realiza a previsão da receita e a fixação da despesa. Por meio dessa Lei, a sociedade visualiza o quanto se espera arrecadar. Entretanto verifica-se que muitos municípios não dão a devida transparência para sua legislação. Os municípios que se destacam na divulgação desses dados são: Angra dos Reis, Areal, Bom Jesus do Itabapoana, Itatiaia, Mesquita, Niterói, Queimados, Silva Jardim, Teresópolis e Volta Redonda. No município de Miguel Pereira, por exemplo, o link sobre legislação está dentro da página da Secretaria de Fazenda. Há necessidade da informação ser de fácil acesso. Identificou-se que $35 \%$ das prefeituras não apresentam a legislação atualizada em seus sites.

17. As etapas da execução orçamentária no tocante a dotação inicial, empenhado, liquidado, pago e restos a pagar estão sendo divulgadas de forma plena por $24 \%$ dos municípios, parcialmente por $24 \%$ e 52\% dos municípios não disponibilizam dados sobre a execução orçamentária. 
18. Quanto a classificação orçamentária: institucional (órgão e unidade orçamentária), funcional programática (função, subfunção, programa, ação, subtítulo), natureza da despesa (categoria econômica, grupo de natureza de despesa, modalidade da aplicação e elemento de despesa). Estão sendo divulgadas totalmente por $13 \%$ dos municípios, parcialmente por $24 \%$ e $63 \%$ dos municípios não disponibilizam dados sobre a classificação orçamentária.

19. A transparência dos atos relacionados a Convênios celebrados pela prefeitura com seus respectivos números, concedente, responsável concedente, data da celebração, data da publicação, vigência, objeto, justificativa e situação do convênio não são divulgados, com exceção dos municípios de Belford Roxo, Niterói, Resende, São João de Meriti e São Pedro da Aldeia que dão algumas informações sobre o assunto.

20. Patrimônio: quantitativo, alocação e valores. A prefeitura de Duque de Caxias e Nova Iguaçu apresentam dados sobre patrimônio. No Portal da Transparência de algumas prefeituras existiam link sobre patrimônio, mas ao ativa-lo verificava-se que não havia nenhuma informação cadastrada, como por exemplo no município de Casemiro de Abreu.

Algumas prefeituras estão divulgando o cronograma de ações para implementação da Contabilidade Aplicada ao Setor Público como: Vassouras, Trajano de Moraes e Santa Maria Madalena. Art. 60 Parágrafo Único da Portaria STN no 828 de 14.12.2011 alterada pela Portaria no 231/2012). Essa portaria tem o objetivo de possibilitar o controle social das ações dos governos relacionadas ao aperfeiçoamento das informações contábeis, determina a publicação do cronograma de ações na internet, com visibilidade para a sociedade.

No período da pesquisa (março e abril de 2015) o site dos municípios: Barra Mansa, Engenheiro Paulo de Frontin e Iguaba Grande estavam em manutenção.

O Ministério Público Federal (MPF) criou um ranking, com base na Lei de Acesso à Informação (Lei 12.527/11), na Lei da Transparência (Lei Complementar no 131/2009) e no Decreto 7.185/10, para averiguar o nível de transparência dos municípios da Baixada Fluminense. Nenhuma das oito cidades avaliadas (Mesquita, Nova Iguaçu, Duque de Caxias, Nilópolis, Queimados, São João do Meriti, Japeri e Belford Roxo) estavam cumprindo integralmente a legislação. Belford Roxo ocupou a ultima posição desse ranking. Diante dessa situação, o procurador da República moveu oito ações civis públicas e uma ação de improbidade administrativa, além de expedir recomendações em fevereiro de 2014.

O quadro 1 apresenta a classificação dos municípios com a maior transparência, entretanto, cabe destacar que a pontuação dos primeiros colocados está muito baixa. A maior nota obtida foi 70 e nenhum município alcançou a nota máxima. $O$ desempenho dos primeiros colocados está aquém do padrão ideal de transparência.

Quadro 1- Municípios com maior transparência

\begin{tabular}{|l|c|c|}
\hline Município & Pontuação & Classificação \\
\hline Resende & 70 & $1^{\circ}$ \\
\hline Mangaratiba & 59 & $2^{\circ}$ \\
\hline Niterói & 56 & $3^{\circ}$ \\
\hline Macaé & 54 & $4^{\circ}$ \\
\hline Itatiaia e Duque de Caxias & 51 & $5^{\circ}$ \\
\hline Rio de Janeiro & 46 & $6^{\circ}$ \\
\hline Bom Jesus do Itabapoana & 45 & $7^{\circ}$ \\
\hline
\end{tabular}


\begin{tabular}{|l|l|c|}
\hline Rio das Ostras, Três Rios e Paraty & 44 & $8^{\circ}$ \\
\hline
\end{tabular}

Fonte: A autora, 2015

O município que alcançou a pontuação mais elevada foi Resende, embora seja a maior nota dentre os 92 municípios, alguns quesitos não foram atendidos como por exemplo a apresentação dos dados sobre despesas com passagens aéreas e diárias concedidas, indicando nome e cargo do beneficiário, destino da viagem, período e motivo da viagem, bem como o número de diárias. Não apresenta as perguntas e respostas mais frequentes da sociedade.

Mangaratiba apresentou uma diferença de 11 pontos em relação ao primeiro colocado e apenas 3 pontos em relação ao terceiro.

Quadro 2- Municípios com menor transparência

\begin{tabular}{|l|c|c|}
\hline Município & Pontuação & Classificação \\
\hline Aperibé & 6 & $44^{\circ}$ \\
\hline Seropédica & 9 & $43^{\circ}$ \\
\hline Belford Roxo, Rio das Flores, São Francisco de Itabapoana e São Fidelis & 10 & $42^{\circ}$ \\
\hline São Sebastião do Alto & 11 & $41^{\circ}$ \\
\hline Itaperuna e Magé & 12 & $40^{\circ}$ \\
\hline Queimados, Macuco & 13 & $39^{\circ}$ \\
\hline Arraial do Cabo, Saquarema e Trajano de Morais & 14 & $38^{\circ}$ \\
\hline Carmo & 15 & $37^{\circ}$ \\
\hline
\end{tabular}

Fonte: A autora, 2015

O município que apresentou o menor índice de transparência no período da pesquisa foi Aperibé, seguido por Seropédica. A diferença entre a pontuação do primeiro e segundo colocado ultrapassa o obtido pelo $44^{\circ}, 43^{\circ}$ e $42^{\circ}$.

Quadro 3 - Municípios situação intermediária

\begin{tabular}{|l|c|c|}
\hline Cardoso Moreira, Mendes e Nova Friburgo & 16 & $36^{\circ}$ \\
\hline São José de Ubá e Cambuci & 17 & $35^{\circ}$ \\
\hline Paracambi & 18 & $34^{\circ}$ \\
\hline Porciúncula & 18,5 & $33^{\circ}$ \\
\hline Bom Jardim, Cachoeiras de Macacu, Natividade, São Gonçalo e Varre Sai & 19 & $32^{\circ}$ \\
\hline Armação de Búzios & 21 & $31^{\circ}$ \\
\hline Itaboraí, Japeri, Petrópolis, Rio Bonito e Vassouras & 22 & $30^{\circ}$ \\
\hline Porto Real & 23 & $29^{\circ}$ \\
\hline São José do Vale do Rio Preto & 23,5 & $28^{\circ}$ \\
\hline Paraíba do Sul, São João da Barra, Araruama, Duas Barras e Laje do Muriaé & 24 & $27^{\circ}$ \\
\hline Rio Claro, Tanguá & 25 & $26^{\circ}$ \\
\hline Quissamã, Sumidouro & 26 & $25^{\circ}$ \\
\hline Guapimirim, Piraí, Santo Antônio de Pádua & 27 & $24^{\circ}$ \\
\hline Cabo Frio & 28 & $23^{\circ}$ \\
\hline Sapucaia & 28,5 & $22^{\circ}$ \\
\hline Quatis, Angra dos Reis, Miguel Pereira & 29 & $21^{\circ}$ \\
\hline Itaocara, Maricá & 30 & $20^{\circ}$ \\
\hline Barra do Pirai, Carapebus & 31 & $19^{\circ}$ \\
\hline Campos dos Goytacazes, Comendador Levy Gasparian, Cordeiro, Santa Maria & 32 & $18^{\circ}$ \\
\hline
\end{tabular}

Revista de Contabilidade e Controladoria, ISSN 1984-6266

Universidade Federal do Paraná, Curitiba, v. 8, n.2, p. 130-143, mai./ago. 2016. 


\begin{tabular}{|l|c|c|}
\hline Madalena & & \\
\hline Conceição de Macabu, Italva, & 33 & $17^{\circ}$ \\
\hline Paty do Alferes, São João do Meriti, Silva Jardim & 34 & $16^{\circ}$ \\
\hline Valença, Teresópolis, Areal, Nova Iguaçu & 35 & $15^{\circ}$ \\
\hline Casimiro de Abreu & 37,5 & $14^{\circ}$ \\
\hline Pinheiral, Volta Redonda & 38 & $13^{\circ}$ \\
\hline São Pedro da Aldeia & 39 & 12 \\
\hline Cantagalo, Miracema & 40 & $11^{\circ}$ \\
\hline Itaguaí, Nilópolis & 41 & $10^{\circ}$ \\
\hline Mesquita, & 43 & $9^{\circ}$ \\
\hline Site Manutenção & & - \\
\hline Barra Mansa, Iguaba Grande e Engenheiro Paulo de Frontin & - & - \\
\hline
\end{tabular}

Fonte: A autora, 2015

A grande maioria dos municípios apresentou pontuação entre 16 e 43 pontos um número muito baixo. $O$ gráfico a seguir apresenta os resultados.

Gráfico 1 - Nível de transparência

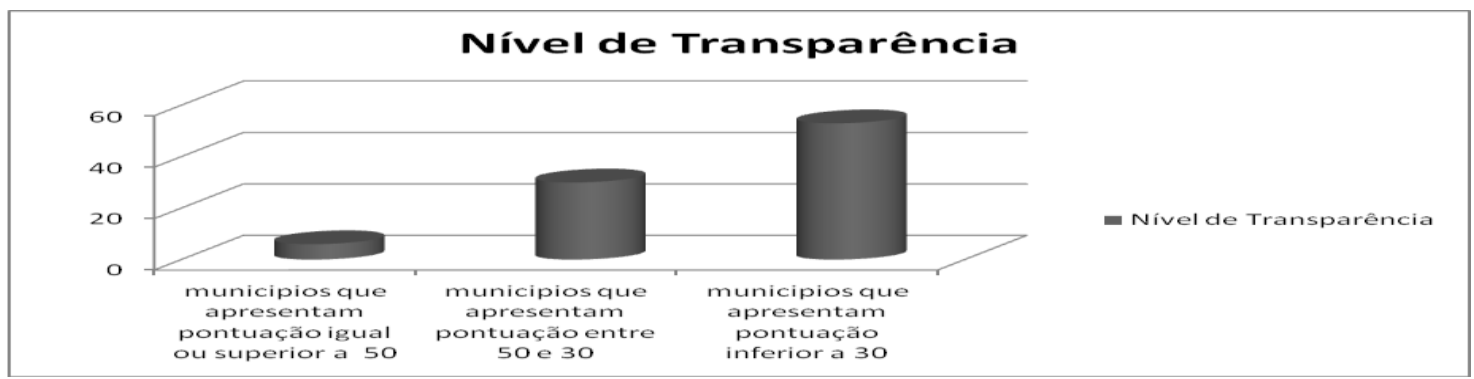

Fonte: A autora, 2015

A maioria dos municípios do Estado do Rio de Janeiro apresenta baixo nível de transparência, 59,55\% obtiveram pontuação inferior a 30 pontos, 33,71\% alcançaram pontuação inferior a 50 e superior a 30 pontos. Os sites com maior nível de transparência correspondem a 6,74\% dos municípios pesquisados. Como haviam 20 quesitos valendo 5 pontos cada, a nota máxima possível seria 100 pontos.

\section{CONCLUSÃO}

A administração pública convive atualmente com legislação sobre os procedimentos a serem desenvolvidos em prol do aumento no nível de transparência das informações, inclusive nos sites das entidades pública. A legislação existente sobre o tema transparência ainda não é uma garantia para a adoção plena dos dispositivos legais. $O$ estudo apresentou um baixo nível de transparência nos sites das prefeituras do Estado do Rio de Janeiro.

A análise no site possibilitou identificar que os dados sobre as despesas apresentam uma linguagem complexa e de difícil entendimento pelo cidadão. Alguns municípios disponibilizam a pesquisa dos 
empenhos emitidos com a seleção de uma data ao invés de permitir a pesquisa em intervalos de meses, dias ou semestres. Em outros casos há necessidade de conhecimento de codificação de orçamento para entender os dados publicados. A liberação em tempo real de informações pormenorizadas sobre a execução orçamentária e financeira, em meios eletrônicos de acesso público, ainda não faz parte da realidade da administração pública. Observa-se que $66 \%$ dos municípios do Estado não disponibilizam dados sobre a execução orçamentária. Alguns municípios apresentaram opções de pesquisa que necessitava de avançado conhecimento de codificação de orçamento para realizá-la. A linguagem utilizada nos sites ainda não é de fácil compreensão por todos.

O estudo identificou dados desatualizados nos sites, como no caso de licitação com a última atualização em 2013 (Maricá), a legislação mais atual era de 2009 no município de Magé. A LAI determina que as entidades precisam manter atualizadas as informações disponíveis para acesso. A ausência da publicidade dos principais mecanismos de planejamento (Lei Orçamentária -LOA, Lei de Diretrizes Orçamentárias - LDO, Plano Plurianual - PPA) dificulta o controle social. O cidadão sem acesso as leis em vigor não consegue acompanhar a execução orçamentária. Há necessidade das entidades divulgarem as receitas previstas, despesas fixadas e o planejamento para os anos seguintes. Bem como apresentar as alterações orçamentárias oriundas dos créditos adicionais. No conjunto, o Estado tem pelo menos um município divulgando informações sobre cada quesito utilizado na pesquisa. Individualmente poucos municípios atendem a maioria dos 20 itens pesquisados. O município de Resende está acima da média e se destaca entre as 92 prefeituras.

Os dados apurados na pesquisa vão ao encontro da pesquisa de Souza, Barros e Araujo (2013) e Staroscky et al (2014) no qual identificou que os municípios pesquisados ainda precisam melhorar o nível de transparência de suas informações, para que os cidadãos possam ter um melhor contato com o que é disponibilizado em seus sites e para que a população possa exercer o controle social mais eficaz perante os atos da gestão pública.

O estudo de Vicente (2014) demonstrou que os municípios ainda apresentam limitação na divulgação dos dados, restringindo a participação da população na gestão pública, no acesso eficiente aos serviços públicos, especialmente sobre o processo de planejamento.

Os primeiros passos para tornar a administração pública mais transparente estão sendo implantados. Algumas prefeituras estão criando novas opções para ampliar o nível de transparência. Agora, há a necessidade de um avanço maior nesse aspecto com a finalidade de atender os interesses da coletividade. As entidades devem garantir a autenticidade e a integridade das informações disponíveis para acesso nos seus sites.

\section{REFERÊNCIAS}

ACKERMAN, J. (2004). Co-governance for accountability: beyond "exit" and "voice". World Development, 32(3), 447-463.

FUMEGA, S. (2014). Alianza Regional por la Libre Expresión e Información. Saber Más VI: Informe Regional Sobre Acesso a Información Pública $Y$ Apelaciones. Disponível em: http:/www.alianzaregional.net/acciones/investigacion-aplicada/sabermasvi/

BERNARDES, Marciele Berger; SANTOS, Paloma Maria; ROVER, Aires José. Ranking das prefeituras da região Sul do Brasil: uma avaliação a partir de critérios estabelecidos na Lei de Acesso à Informação. Revista de Administração Pública, v. 49, n. 3, p. 761-792, 2015. 
BOVENS, M. A. (2006). Analysing and Assessing Public Accountability. A Conceptual Framework. European Governance Papers (EUROGOV), 100, 1-37.

COLLIS, J., e HUSSEY, R. (2005). Pesquisa em administração: um guia prático para alunos de graduação e pós-graduação. 2. ed. Porto Alegre: Bookman.

Controladoria Geral da União curso "Rumo a uma cultura de acesso à informação: a Lei 12.527/2011" https://escolavirtual.cgu.gov.br/ead/mod/book/print.php?id=497

HOCH, P. A., RIGUI, L. M., \& da Silva, R. L. (2013). Desafios à concretização da transparência ativa na internet, à luz da lei de acesso à informação pública: análise dos portais dos Tribunais Regionais Federais. Revista Direitos Emergentes na Sociedade Global, 1(2), 257-286.

MATIAS-PEREIRA, J. (2012). Manual de gestão pública contemporânea. 4. ed. São Paulo: Atlas

MEDEIROS, A. D., CRANTSCHANINOV, T. I., e SILVA, F. D. (2013). Estudos sobre accountability no Brasil: meta-análise de periódicos brasileiros das áreas de administração, administração pública, ciência política e ciências sociais. Revista de Administração Pública, Rio de Janeiro, 47(3), 745-775.

MARENGO, TREJES, Sabrina e DIEHL Carlos Alberto. "A Possibilidade do Controle Social Mediante o Acesso a Informações em Sites dos Municípios Gaúchos." Contabilidade, Gestão e Governança 14.3 (2011).

O 'DONNELL, G (1998). Accountability horizontal e novas poliarquias. Lua Nova [online], n.44, p. 2754, ISSN 0102-6445.

RAUPP, F. M. (2014). Prestação de contas de executivos municipais de Santa Catarina: uma investigação nos portais eletrônicos. Administração Pública e Gestão Social, 6(3), 151-158.

VIANA de Souza, F. J., da Costa Barros, C., de Araujo, F. R., e da Silva, M. C. (2013). Índice de transparência municipal: um estudo nos municípios mais populosos do Rio Grande do Norte. Revista de Gestão, Finanças e Contabilidade, 3(3), 94-113.

SACRAMENTO, Ana Rita Silva; PINHO, José Antônio Gomes. Transparência na Administração Pública: o que mudou depois da Lei de Responsabilidade Fiscal? Um estudo exploratório em seis municípios da Região Metropolitana de Salvador. Revista de Contabilidade da UFBA, v. 1, n. 1, p. 48-61, 2008.

STAROSCKY, E. A., NUNES, G. S. D. F., Leão Lyrio, M. V., e Lunkes, R. J. (2014). A Transparência dos Portais Municipais sob a Perspectiva da Legislação Brasileira: o caso de prefeituras em Santa Catarina. REUNA, 19(1), 29-52.

VICENTE, E. F. R.,e SCHEFFER, E. D. O. (2014). Governança e Internet: um estudo de caso sobre a divulgação de dados da Administração Pública sob a ótica dos princípios da governança pública-doi: 10.5102/un. gti. v.3i2. 2412. Universitas: Gestão e TI, 3(2).

ZHENG, Y., SCHACHTER, H. L., e HOLZER, M. (2014). The impact of government form on eparticipation: A study of New Jersey municipalities. Government Information Quarterly, 31(4), 653659. doi: http://dx.doi.org/10.1016/j.giq.2014.06.004

WEHNER, Joachim, and RENZIO Paolo de. Citizens, Legislators, and Executive disclosure: the political determinants of fiscal transparency. In-depth Research on Budget Transparency, Participation, and Accountability. World Development 41 (January): 96- 108. 2013 